\section{Intestinal parasitic infections in Okada rural community, Edo State, Nigeria: a four year retrospective study}

\author{
Bankole H. Oladeinde, ${ }^{1}$ \\ Richard Omoregie, ${ }^{2}$ Mitsan Olley, ${ }^{3}$ \\ Ahamdi J. Anunibe, ${ }^{3}$ Ikponmwosa Odia ${ }^{4}$ \\ 'Department of Medical Microbiology, \\ College of Health Sciences, Igbinedion \\ University, Okada; ${ }^{2}$ School of Medical \\ Laboratory Sciences, University of Benin \\ Teaching Hospital, Benin City; \\ ${ }^{3}$ Department of Pathology, Igbinedion \\ University Teaching Hospital, Okada; \\ ${ }^{4}$ Institute of Laser Fever Research and \\ Control, Irrua Specialist Hospital, Irrua, \\ Nigeria
}

\section{Abstract}

Intestinal parasitic infections are associated with morbidity and mortality worldwide. Data on prevalence of intestinal parasitic infection is sparse in rural Nigeria. Against this background, this study aimed at determining the prevalence of intestinal parasitic infections within a four year period in the rural community of Okada, Edo State, Nigeria. Fecal samples obtained from 1528 patients (consisting of 740 males and 788 females) presenting with signs and symptoms of gastroenteritis at the Igbinedion University Teaching Hospital, Okada were examined for presence of ova, cyst and trophozoites of parasites using standard methods. Patient's age ranged from 6 months to 73 years. Study was conducted between 2007 and 2010. The prevalence of intestinal parasitic infections increased significantly $(\mathrm{P}=0.003)$ from $14.7 \%$ in 2007 to $22.5 \%$ in 2010 . In the study period, gender did not affect the prevalence of intestinal parasitic infection ( $\mathrm{P}>0.05)$. Patients within $<1-10$ years had significantly higher prevalence of intestinal parasitic infection. Ascaris lumbricoides was the most predominant parasitic agent, while Schistosoma japonicum was the least prevalent. With respect to parasite, males were observed to have consistently higher prevalence of Entamoeba histolytica infection. The prevalence of intestinal parasitic infection was observed to significantly increase from 2007 to 2010. Age was a risk factor for acquiring intestinal parasitic infection. Ascaris lumbricoides was the most predominant parasitic agent in all years of study. Control and prevention measures are advocated.

\section{Introduction}

Intestinal parasitic infections are among the most common infections worldwide and about 3.5 billion persons, mostly children, are estimated to be infected. ${ }^{1}$ Intestinal parasitic infections affect nutritional status, physical development, mental function and alertness, verbal ability, and inhibition control aspects of cognitive behaviour in children. ${ }^{2}$ Intestinal parasitic infections deprive the poorest of health, contributing to economic instability and social marginalization. ${ }^{3}$ Death and other serious complications can occur if cases of intestinal parasitosis are left untreated especially in children. ${ }^{1}$

In Nigeria, intestinal parasitic infection constitutes a major public health challenge. ${ }^{4}$ Poorly planned housing, improper waste disposal, gross environmental pollution and poor environmental situations among others are driving forces for this observation. ${ }^{5}$ Illiteracy, absence of clean drinking water, and poverty has been shown to promote infection with intestinal parasites ${ }^{3}$ and these factors are rife in most rural communities in Nigeria. ${ }^{6,7}$ Although data on prevalence of human intestinal parasitic infection in Nigeria is common, there is no published data from Okada community, Edo State, Nigeria. Monitoring of disease and assessment of effectiveness of intervention effort in any community is largely enhanced by the availability of local prevalence statistics over a period of time. This type of data is missing in Okada community, and very sparse in many rural communities of Nigeria. Against this background, this study aimed at determining the prevalence of intestinal parasitic infection in Okada (a rural community in Edo State, Nigeria) within a 4 year period.

\section{Materials and Methods}

\section{Study area}

Okada, a rural community, is the headquarters of Ovia North East Local Government Area of Edo-state, Nigeria. The Local Government has an estimated population of 155,344 people. ${ }^{8}$ Majority of the residents of Okada are farmers with few civil servants, lecturers and students making less than $5 \%$ of the community. The study was carried out at Igbinedion University Teaching Hospital, Okada, Edo State, Nigeria, from January 2007 to December 2010. Some neighboring rural communities (villages) also attend the Hospital.

\section{Study population}

This is a laboratory retrospective study. A total of 1528 patients aged 6 months to 73 years with signs and symptoms of gastroen-
Correspondence: Bankole Henry Oladeinde, Department of Medical Microbiology, College of Health Sciences, Igbinedion University, Okada, Nigeria.

Tel.Fax: +234.80253096120.

E-mail: bamenzy@yahoo.com

Key words: intestinal parasite, rural community, Nigeria.

Contributions: BHO, MO and AJA took part in study design, generated and analysed data, and substantively drafted the article. RO and IO took part in study design, analysed data and substantively drafted the article.

Conflict of interests: the authors declare no potential conflict of interests.

Acknowledgements: the authors acknowledge all members of the ethical committee of Igbinedion University Teaching Hospital for giving their approval for this study.

Received for publication: 18 August 2013.

Revision received: 13 September 2013.

Accepted for publication: 25 September 2013.

This work is licensed under a Creative Commons Attribution 3.0 License (by-nc 3.0).

(C) Copyright B.H. Oladeinde et al., 2014

Licensee PAGEPress, Italy

Healthcare in Low-resource Settings 2014; 2:1891 doi:10.4081/hls.2014.1891

teritis were included in this study. They consisted of 740 males and 788 females. Informed consent was obtained from all patients or their parents/guardian in case of children prior to specimen collection. The study was approved by the Ethical committee of the Igbinedion University Teaching Hospital, Okada, Edo State, Nigeria.

\section{Collection and processing of specimens}

Stool specimens were collected from each patient in wide mouthed containers and examined microscopically for ova, cysts or protozoa using saline and iodine mount as previously described. ${ }^{9}$

\section{Statistical analysis}

The data obtained were analyzed using Chi square $\left(\chi^{2}\right)$ test and odds ratio analysis using the statistical software INSTAT ${ }^{\circledR}$ (Graphpad software Inc., La Jolla, CA, USA). Statistical significance was set at $\mathrm{P}<0.05$.

\section{Results}

A total of $278(18.2 \%)$ of the 1528 patients 
were infected with at least one intestinal parasite. The prevalence of intestinal parasitic infections was observed to significantly $(\mathrm{P}=0.003)$ increase from 2007 to 2010. Among patients with intestinal parasitic infection, 30 (10.8\%) had more than one parasite in their stool. No statistically significant difference $(\mathrm{P}=0.733)$ was observed over the years with respect to the prevalence of mixed intestinal parasitic infection (Table 1). Gender was not significantly associated with intestinal parasitic infection in all the study period (Table 2). The prevalence of intestinal parasitic infections was significantly higher in the age group $<1-10$ years from 2007 to 2010. Among participants aged $<1-10$ years, the prevalence of intestinal parasitic infection was observed to significantly increase from 2006 to 2010 (Table 3). A total of 308 intestinal parasites were identified in 278 patients. Generally, and in all the years of study, Ascaris lumbricoides was the most predominant parasitic agent identified in patients stool, followed by Entamoeba Histolytica. Schistosama. japonicum was the least prevalent intestinal parasitic agent (Table 4). The prevalence of Entamoeba histolytica infection was observed to be higher among male participants in all years of study (Table 5).

\section{Discussion}

Intestinal parasitic infections are globally endemic and have been described as constituting the greatest single cause of illness and disease worldwide. ${ }^{3}$ Factors that promote intestinal parasitic infections, i.e. illiteracy, poverty, absence of clean drinking water, ${ }^{3}$ are rife in rural communities in Nigeria. Against this background and the paucity of reports on intestinal parasitic infections in rural communities of Edo State, Nigeria, this study was conducted. The overall prevalence of intestinal parasitic infection in this study was $18.2 \%$. This is lower than reported figures in other Nigerian studies., ${ }^{5,10,11}$ The prevalence of intestinal para- sitic infections varies with different geographical regions. ${ }^{12}$ The variation could be due to differences in geographical location: in Ikeh et $a l .,{ }^{5}$ Nduka et al., ${ }^{10}$ and Awolaju and Morenikeji, ${ }^{11}$ studies were conducted in north central, south eastern, and south western Nigeria respectively, in contrast to our study which was conducted in Mid Western Nigeria.

The prevalence of intestinal parasitic infection was observed to significantly increase from $14.7 \%$ in 2007 to $22.5 \%$ in 2010 . Igbinedion University, Nigeria's first private University in Okada, has witnessed an unprecedented influx of persons into the community, without corresponding increases in social amenities, like portable drinking water amongst others. This is likely to result in more people sharing limited social amenities such as portable drinking water, and housing which in turn could precipitate the spread of intestin- al parasitic infections observed over the years in this study. Thirty patients representing $10.8 \%$ of the total number of patients with intestinal parasitic infection in this study had more than one parasite recovered from their stool. However, the prevalence of mixed infection did not differ significantly from 2007 to 2010. Irrespective of year of study, gender did not significantly affect the prevalence of intestinal parasitic infection. This is consistent with other reports. ${ }^{5,10}$ Age was found to significantly affect the prevalence of intestinal parasitic infection with participants within the age group of $<1-10$ years consistently observed to have the highest prevalence within each year of study. Similar findings have been reported elsewhere. ${ }^{13}$ Among patients within the age group of $<1-10$ years, the prevalence of intestinal parasitic infection was observed to significantly $(\mathrm{P}=0.001)$ increase from $21.2 \%$ in 2007

Table 1. Four year prevalence of intestinal parasitic infection in Okada.

\begin{tabular}{lcccc} 
Year & $\begin{array}{c}\text { No. of tested } \\
\text { patients }\end{array}$ & $\begin{array}{c}\text { No. of infected } \\
\text { patients (\%) }\end{array}$ & $\begin{array}{c}\text { Mixed infection } \\
(\%)\end{array}$ & P \\
\hline 2007 & 218 & $32(14.7)$ & $5(15.6)$ & 0.003 \\
2008 & 454 & $72(15.9)$ & $7(9.7)$ & - \\
\hline 2009 & 350 & $60(17.1)$ & $5(8.3)$ & - \\
2010 & 506 & $114(22.5)$ & $13(11.4)$ & - \\
\hline Total & 1528 & $278(18.2)$ & $30(10.8)$ & - \\
\hline
\end{tabular}

Table 2. Effect of gender on prevalence of intestinal parasitic infection in Okada.

\begin{tabular}{ccccccc} 
Year & Gender & $\begin{array}{c}\text { No. of tested } \\
\text { patients }\end{array}$ & $\begin{array}{c}\text { No. of infected } \\
\text { patients (\%) }\end{array}$ & OR & $95 \%$ CI & P \\
2007 & Female & 113 & $21(18.6)$ & 1.951 & $0.890,4.273$ & 0.134 \\
& Male & 105 & $11(10.5)$ & 0.513 & $0.234,1.123$ & \\
2008 & Female & 265 & $43(16.2)$ & 1.069 & $0.639,1.785$ & 0.902 \\
& Male & 189 & $29(15.3)$ & 0.936 & $0.560,1.563$ & \\
\hline 2009 & Female & 186 & $33(17.7)$ & 1.094 & $0.626,1.913$ & 0.861 \\
& Male & 164 & $27(16.5)$ & 0.913 & $0.523,1.597$ & \\
2010 & Female & 282 & $65(23.0)$ & 1.070 & $0.702,1.630$ & 0.836 \\
& Male & 224 & $49(21.3)$ & 0.935 & $0.614,1.424$ & \\
\hline
\end{tabular}

$\mathrm{OR}$, odds ratio; $\mathrm{CI}$, confidence interval.

Table 3. Effect of age on prevalence of intestinal parasitic infection in Okada.

\begin{tabular}{|c|c|c|c|c|c|c|c|c|c|}
\hline \multirow{2}{*}{$\begin{array}{l}\text { Age } \\
\text { (year) }\end{array}$} & \multicolumn{2}{|c|}{2007} & \multicolumn{2}{|c|}{2008} & \multicolumn{2}{|c|}{2009} & \multicolumn{2}{|c|}{2010} & \multirow[t]{2}{*}{$\mathbf{P}$} \\
\hline & $\begin{array}{l}\text { No. of } \\
\text { tested } \\
\text { patients }\end{array}$ & $\begin{array}{c}\text { No. of } \\
\text { infected } \\
\text { patients (\%) }\end{array}$ & $\begin{array}{l}\text { No. of } \\
\text { tested } \\
\text { patients }\end{array}$ & $\begin{array}{l}\text { No. of } \\
\text { infected } \\
\text { patients (\%) }\end{array}$ & $\begin{array}{l}\text { No. of } \\
\text { tested } \\
\text { patients }\end{array}$ & $\begin{array}{c}\text { No. of } \\
\text { infected } \\
\text { patients (\%) }\end{array}$ & $\begin{array}{l}\text { No. of } \\
\text { tested } \\
\text { patients }\end{array}$ & $\begin{array}{c}\text { No. of } \\
\text { infected } \\
\text { patients (\%) }\end{array}$ & \\
\hline$\leq 1-10$ & 80 & $17(21.2)$ & 155 & 38 (24.5) & 115 & $29(25.2)$ & 168 & $68(40.4)$ & 0.001 \\
\hline $11-20$ & 47 & $8(17.0)$ & 80 & $15(18.8)$ & 58 & $13(22.4)$ & 77 & $18(23.4)$ & 0.326 \\
\hline 21-30 & 19 & $2(10.5)$ & 44 & $5(10.6)$ & 30 & $2(6.6)$ & 65 & $6(24.6)$ & 0.727 \\
\hline $31-40$ & 23 & $1(4.3)$ & 41 & $4(9.7)$ & 39 & $4(10.2)$ & 48 & $5(10.4)$ & 0.490 \\
\hline $41-50$ & 14 & $1(7.1)$ & 47 & $3(6.3)$ & 41 & $3(7.3)$ & 60 & $4(6.7)$ & 0.995 \\
\hline $51-60$ & 18 & $0(0.0)$ & 33 & $4(12.1)$ & 25 & $3(12.0)$ & 44 & $6(13.6)$ & 0.207 \\
\hline$\geq 60$ & 17 & $3(17.6)$ & 54 & $3(5.6)$ & 42 & $6(14.3)$ & 44 & $7(15.9)$ & 0.411 \\
\hline
\end{tabular}

$\mathrm{P}=0.036$ (2007); $\mathrm{P}<0.0001$ (2008); $\mathrm{P}=0.007$ (2009); $\mathrm{P}<0.0001$ (2010). 
Table 4. Yearly distribution of intestinal parasites in Okada.

\begin{tabular}{lccccc} 
Parasite & \multicolumn{5}{c}{ No. of infected patients (\%) } \\
& 2007 & 2008 & 2008 & 2009 & 2010 \\
A. lumbricoides & $21(56.7)$ & $46(58.2)$ & $33(50.8)$ & $62(48.8)$ & $162(52.6)$ \\
Hookworm & $5(13.5)$ & $10(12.7)$ & $11(16.9)$ & $22(17.3)$ & $48(15.6)$ \\
\hline E. vermicularis & $2(5.4)$ & $3(3.8)$ & $1(1.5)$ & $3(2.3)$ & $9(2.9)$ \\
S. stercoralis & $0(0.0)$ & $2(2.5)$ & $1(1.5)$ & $3(2.3)$ & $6(1.9)$ \\
\hline S. japonicum & $0(0.0)$ & $1(1.3)$ & $0(0.0)$ & $1(0.8)$ & $2(0.6)$ \\
E. histolytica & $8(21.6)$ & $15(18.9)$ & $18(27.7)$ & $34(26.8)$ & $75(24.4)$ \\
\hline G. lamblia & $1(2.7)$ & $2(2.5)$ & $1(1.5)$ & $2(1.5)$ & $6(1.9)$ \\
Total & $37(12.0)$ & $79(25.6)$ & $65(21.1)$ & $127(41.2)$ & $308(0.1)$ \\
\hline
\end{tabular}

Table 5. Gender distribution of intestinal parasites in Okada.

\begin{tabular}{|c|c|c|c|c|c|c|c|c|}
\hline \multirow[t]{3}{*}{ Parasite } & \multicolumn{6}{|c|}{ No. of infected patients (\%) } & \multirow{2}{*}{\multicolumn{2}{|c|}{2010}} \\
\hline & \multicolumn{2}{|c|}{2007} & \multicolumn{2}{|c|}{2008} & \multicolumn{2}{|c|}{2009} & & \\
\hline & M & $\mathbf{F}$ & M & $\mathbf{F}$ & M & $\mathbf{F}$ & M & $\mathrm{F}$ \\
\hline A. lumbricoides & $7(58.3)$ & $14(56.0)$ & $15(48.4)$ & $31(64.6)$ & $12(37.5)$ & $21(63.6)$ & $35(49.3)$ & $27(48.2)$ \\
\hline Hookworm & $1(8.3)$ & $4(16.0)$ & $3(9.6)$ & $7(14.5)$ & $9(28.1)$ & $2(6.1)$ & $10(14.1)$ & $12(21.9)$ \\
\hline E. vermicularis & $1(8.3)$ & $1(4.0)$ & $2(6.5)$ & $1(2.1)$ & $0(0.0)$ & $2(6.1)$ & $2(2.8)$ & $1(1.8)$ \\
\hline S. stercoralis & $0(0.0)$ & $0(0.0)$ & $1(3.2)$ & $1(2.1)$ & $1(3.1)$ & $1(3.0)$ & $3(4.2)$ & $0(0.0)$ \\
\hline S. japonicum & $0(0.0)$ & $0(0.0)$ & $0(0.0)$ & $1(2.1)$ & $0(0.0)$ & $0(0.0)$ & $0(0.0)$ & $1(1.8)$ \\
\hline E. histolytica & $3(25.0)$ & $5(20.0)$ & $8(25.8)$ & $7(14.6)$ & $9(28.1)$ & $9(27.2)$ & $21(29.6)$ & $13(23.2)$ \\
\hline G. lamblia & $0(0.0)$ & $1(4.0)$ & $2(6.5)$ & $0(0.0)$ & $1(3.1)$ & $0(0.0)$ & $0(0.0)$ & $2(3.6)$ \\
\hline
\end{tabular}

$\mathrm{M}$, male; F, female.

to $40.4 \%$ in 2010 . This represents increasing risk of acquiring intestinal parasitic infection for children of this age group living in study location. Children within this age group are likely to be involved in domestic chores of getting water for household use, and this increases exposure to water borne diseases. Also infants may consume food and water of poor hygienic quality, thus increasing their susceptibility to infection. These may explain the high prevalence of intestinal parasitic infections in the age group of $<1-10$ years. However this observation is not consistent with reports elsewhere. ${ }^{5,10}$

Ascaris lumbricoides was the most predominant parasitic agent generally and in all the years of study, followed by Entamoeba histolytica. This finding agrees with a previous report. ${ }^{14}$ Poor socio-economic conditions are among the key factors linked with higher prevalence of ascariasis, as are poor defaecation practices, agricultural factors, housing style, and social class. ${ }^{15}$ Residents of Okada and neighboring villages are mostly farmers, who may engage in agricultural practices that fuel the spread of Ascaris lumbricoides among the population. The finding that Entamoeba histolytica was higher among male participants, have been reported in an earlier study. ${ }^{16}$ The reason for this however is unclear.

\section{Conclusions}

This study reports a high prevalence of intestinal parasitic infection in Okada rural community, which was observed to increase steadily from 2007 to 2010 . Children between 1-10 years had the highest risk of being infected with intestinal parasites. Provision of essential social amenities such as housing and portable drinking water for the teeming population of Okada community by relevant agencies will help in curbing the spate of the disease. Regular screening and treatment of persons infected with intestinal parasites by local health authorities and other intervention agencies are also advocated. Increased public enlightenment on the need for the development of a culture of general environmental cleanliness and personal hygiene among residents of Okada community and environs will also help in stemming intestinal parasitic infections in the bud.

\section{References}

1. Houmisou RS, Amita EU, Olusi TA. Prevalence of intestinal parasites among primary school children in Makurdi, Benue State, Nigeria. Internet J Infect Dis 2010;8:97-106.
2. Nokes CL, Bundy DAP. Does helminthes infection affect mental processing and educational achievement? Parasitol Today 1994;11:14-8.

3. Mehraj V, Hatcher J, Akhtar S, et al. Prevalence and risk factors associated with intestinal parasitic infections among children in an urban slump of Karachi. PLoS One 2008;3:1-7.

4. Uneke CJ, Nnachi MI, Arua U. Assessment of polyparasitim with intestinal parasitic infections and urinary schistosomiasis among school children in a semi-urban area of south eastern Nigeria. Internet $\mathbf{J}$ Health 2009;9:1.

5. Ikeh EJ, Obadofin M0, Brindeiro B, et al. Intestinal parasitism in rural and urban areas of North Central Nigeria: an update. Internet J Microbiol 2006;2:1.

6. Imoh AN, Isaac KJ, Nwanchukwu E0. Comparative analysis of poverty status of community participation in rural development projects of Akwa-Ibom State, Nigeria. New York Sci J 2009;2:68-75.

7. Aderamo AJ, Magaji SA. Rural transportation and the distribution of public facilities in Nigeria: a case of Edu local government area of Kwara State. J Hum Ecol 2010;29: 171-9.

8. National Population Commission. Population and housing census of the Federal Republic of Nigeria. 2006. Available from: http://www.population.gov. ng/index.php/publications/list-of-publications

9. Akinbo FO, Okaka CE, Omoregie R. Prevalence of intestinal parasitic infections among HIV patients in Benin City, Nigeria. Libyan J Med 2010;5:5506.

10. Nduka FO, Nwango VO, Nwanchukwu NC. Human intestinal parasitic infection in Ishiagu- a lead mining area of Abia State. Anim Res 2006;3:505-7.

11. Awolaju BA, Morenikeji OA. Prevalence and intensity of intestinal parasites in five communities in south-west Nigeria. Afr J Biotechnol 2009;8:5542-6.

12. Ramana KV. Intestinal parasitic infections: an overview. Ann Trop Med Pub Health 2012;5:279-81.

13. Akinbo FO, Omoregie R, Eromwon R, et al. Prevalence of intestinal parasites among patients of a tertiary hospital in Benin city, Nigeria. N Am J Med Sci 2011;3:462-4.

14. Dibua UE, Awagu OJ, Esimone CO. Prevalence of intestinal parasitoses in the Nsukka community of South Eastern Nigeria. Int J Trop Med 2007;2:33-40.

15. O'Lorcain P, Holland CV. The public health importance of Ascaris lumbricoides. Parasitology 2000;121:61-71.

16. Acuna-soko R, Maguire JH, Wirth DF. Gender distribution in asymptomatic and invasive amebiasis. Am J Gastroenterol 2000;95:1277-83. 